\title{
Study on Irreversible Change of Magnetic Properties of Some Ferromagnetic Minerals
}

\author{
Mituko OzIMA \\ Geophysical Institute, University of Tokyo \\ and \\ E.E. LARSON \\ Department of Geology, University of Colorado \\ (Received February 20, 1967)
}

\begin{abstract}
Magnetic minerals separated from some acidic rocks undergo an irreversible change in Curie point and saturation magnetization when they are heated in vacuum : both Curie point and saturation magnetization decrease. Microscopic observation of polished sections reveal that all rocks which show such irreversible changes contain, in addition to titanomagnetite, some amount of titanomaghemite. All the other experimental resules such as chemical, Xray and low-temperature thermomagnetic analyses indicate that the irreversible change reflects a break down of the $\gamma$-phase titanomaghemite to the $\alpha$-phase ilmenite-hematite series during heating.
\end{abstract}

\section{Introduction}

Some magnetic minerals commonly show an irreversible change in their Curie point and/or in the intensity of saturation magnetization when they are heated in vacuum (Akimoto, 1951, 1955; Akimoto and Katsura, 1959; Nagata, 1961). An increase in Curie point and in saturation magnetization can generally be explained on the basis of (i) oxidation of titanomagnetite to titanomaghemite, or (ii) production of magnetite due to reduction of hematite. On the other hand, the decrease in Curie point and/or in saturation magnetization can be explained by (i) reduction of titanomaghemite to titanomagnetite, (ii) development of hematite by partial oxidation or by decomposition of maghemite. In more complex cases, high-temperature oxidation can cause an upward change in the Curie point and/or in the magnetic moment (Buddington and Lindsley, 1964; Larson et al, 1967). The purpose of the present paper is to study that type of irreversible change in which both the Curie point and the magnetic moment decrease during heating in vacuum. The mechanism of this irreversible change in magnetic properties is also investigated.

\section{Experimental results}

Fig. 1-a and 1-b show two typical examples of the irreversible change in a thermomagnetic curve for magnetic minerals separated from andesitic rocks. As seen in the figures, the Curie point and the saturation magnetization decrease during the first heating in vacuum. 


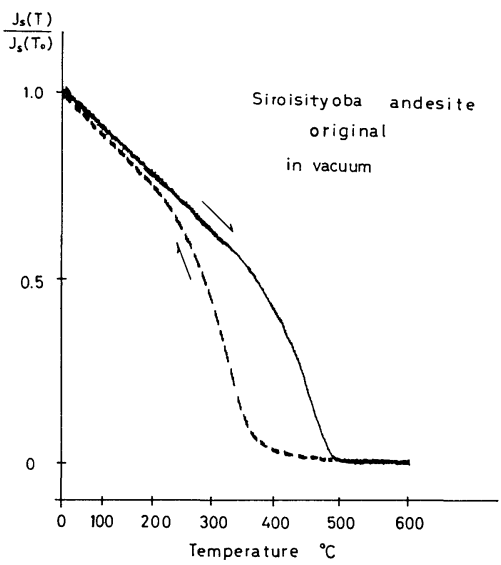

Fig. 1-a

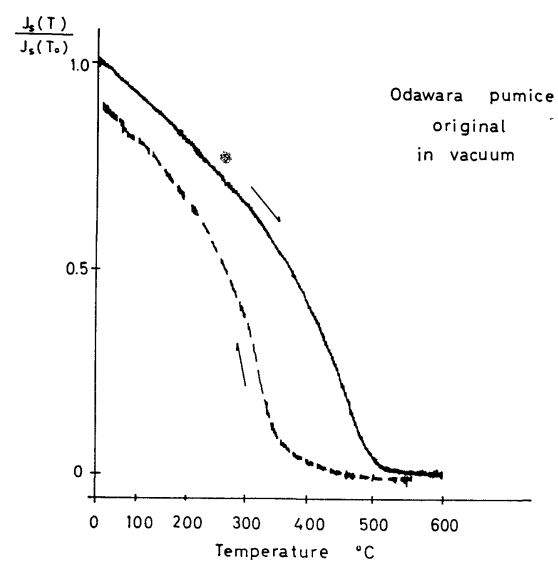

Fig. 1-b

Fig. 1-a, 1-b Thermomagnetic curve $\left(J_{s}-T\right)$ for original Siroisityoba (1-a) and Odawara (1-b) sample. The experiment was carried out in vacuum of about $10^{-3} \mathrm{mmHg}$. The arrows indicate heating and cooling processes.

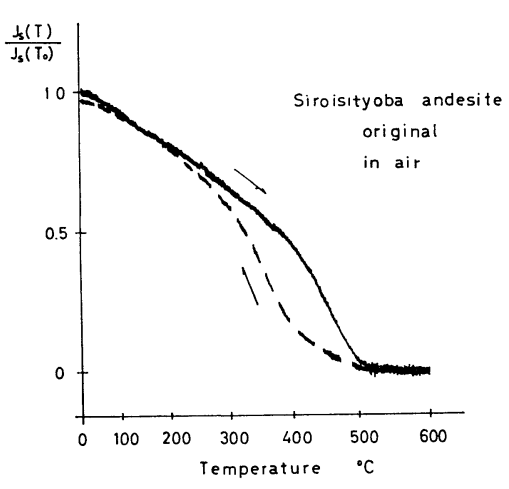

Fig. 1-c

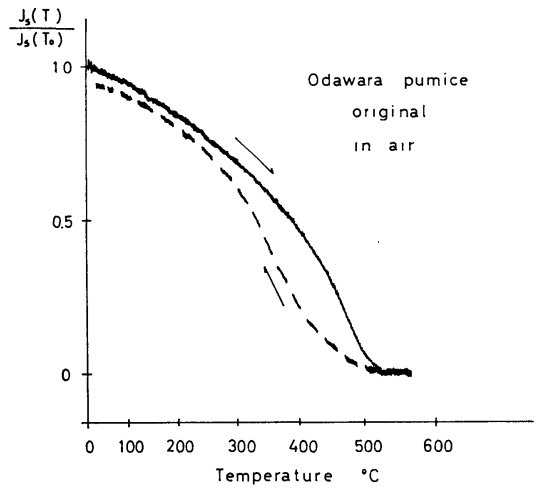

Fig. 1-d

Fig. 1-c, 1-d. Thermomagnetic curve $\left(J_{s}-T\right)$ for original Siroisityoba (1-c) and Odawara (1-d) sample. The experiment was carried out in air.

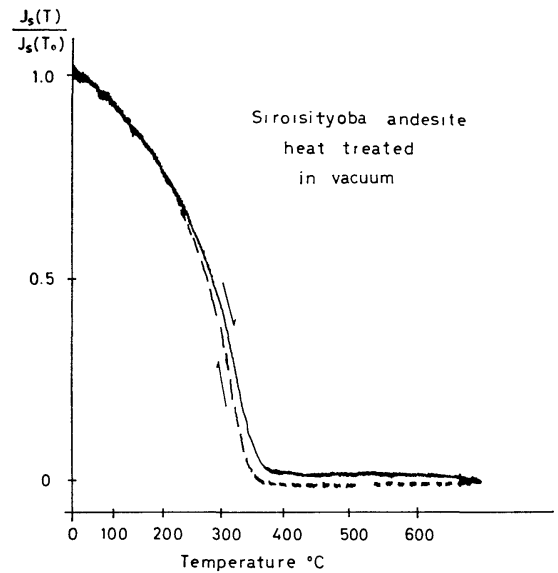

Fig. 1-e

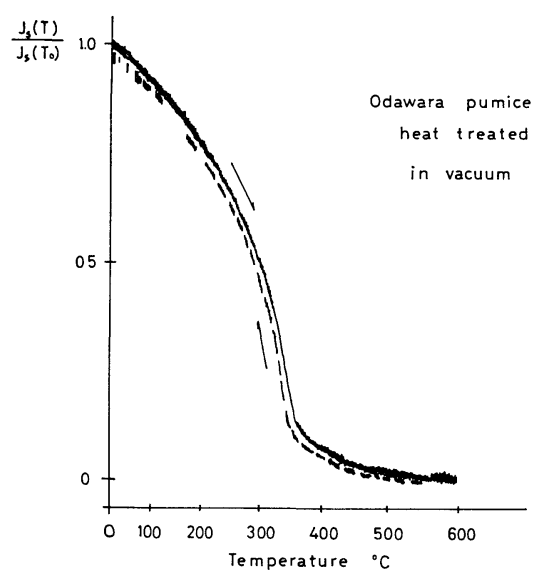

Fig. 1-f

Fig. 1-e, 1-f. Thermomagnetic curve $\left(J_{s}-T\right)$ for Siroisityoba sample (1-e) and Odawara sample (1-f) which were previously heat-treated in vacuum of about $10^{-3}$ $\mathrm{mmHg}$ at $700^{\circ} \mathrm{C}$ for 20 hours. The experiment was carried out in vacuum of about $10^{-3} \mathrm{mmHg}$. 


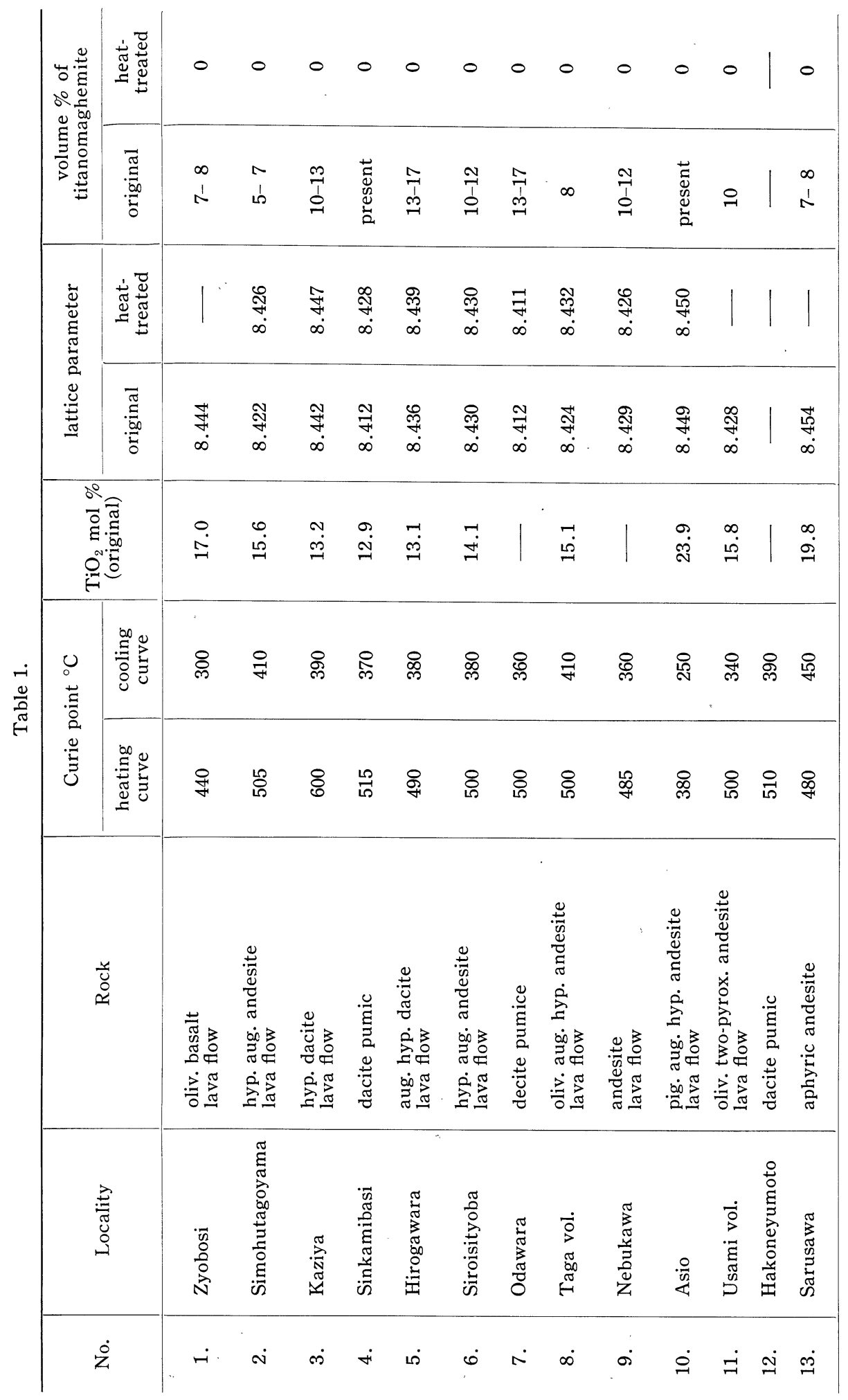


If the heating-cooling cycle is repeated in vacuum, no further change in the magnetic properties occurs and the thermomagnetic curves become fully reversible. If, however, the thermomagnetic analysis is carried out in air, the irreversible change is not as conspicuous (Fig. 1-c, 1-d). A further interesting feature of such an irreversible change is that if the samples were previously heated in vacuum at about $700^{\circ} \mathrm{C}$ for 20 hours, the heat-treated samples do not show the irreversible change (Fig. 1-e, 1-f): the thermomagnetic curves are reversible and similar to the cooling curves in Fig. 1-a and 1-b.

In Table 1 are listed various parameters of 13 typical samples which magnetically display irreversible changes during heating. These parameters include: the Curie points determined both from the heating and cooling $J_{s}$ T curves, $\mathrm{TiO}_{2}$ content, the result of Xray analysis of the magnetic minerals and the microscopic observation of polished sections. Of these samples, the Siroisityoba andesite is examined in detail. Fig. 2-a and 2-b show the temperature dependence of the magnetization acquired in a magnetic field of $25 \mathrm{Oe}$ and changes in the bulk coercive force of the magnetic minerals from this andesite after various heat-treatments in vacuum. It is clear from the figure that the irreversible change in its Curie point takes place at about $500^{\circ} \mathrm{C}$. In Table 2 , the lattice parameters and the chemical

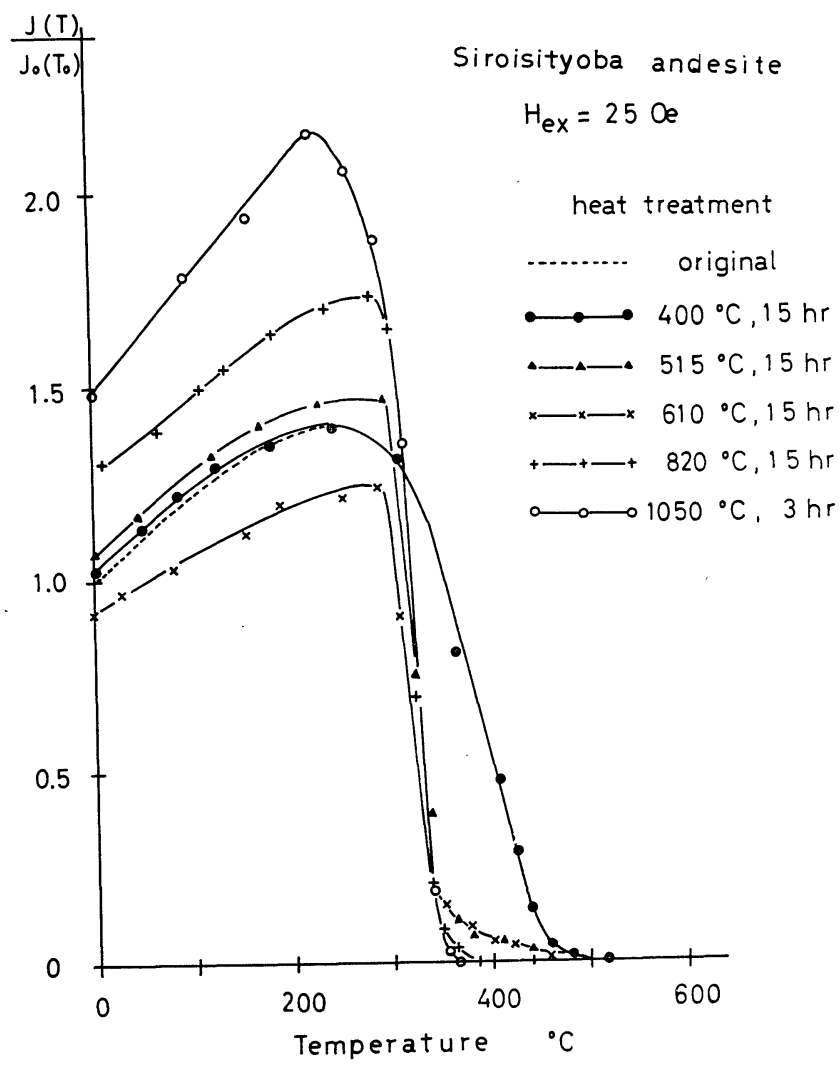

Fig. 2-a Thermomagnetic curves $\left(H_{e x}=25 \mathrm{Oe}\right)$ for heat-treated samples (Siroisityoba) at various temperatures in vacuum of about $10^{-3} \mathrm{mmHg}$. The curve indicates only heating process. 


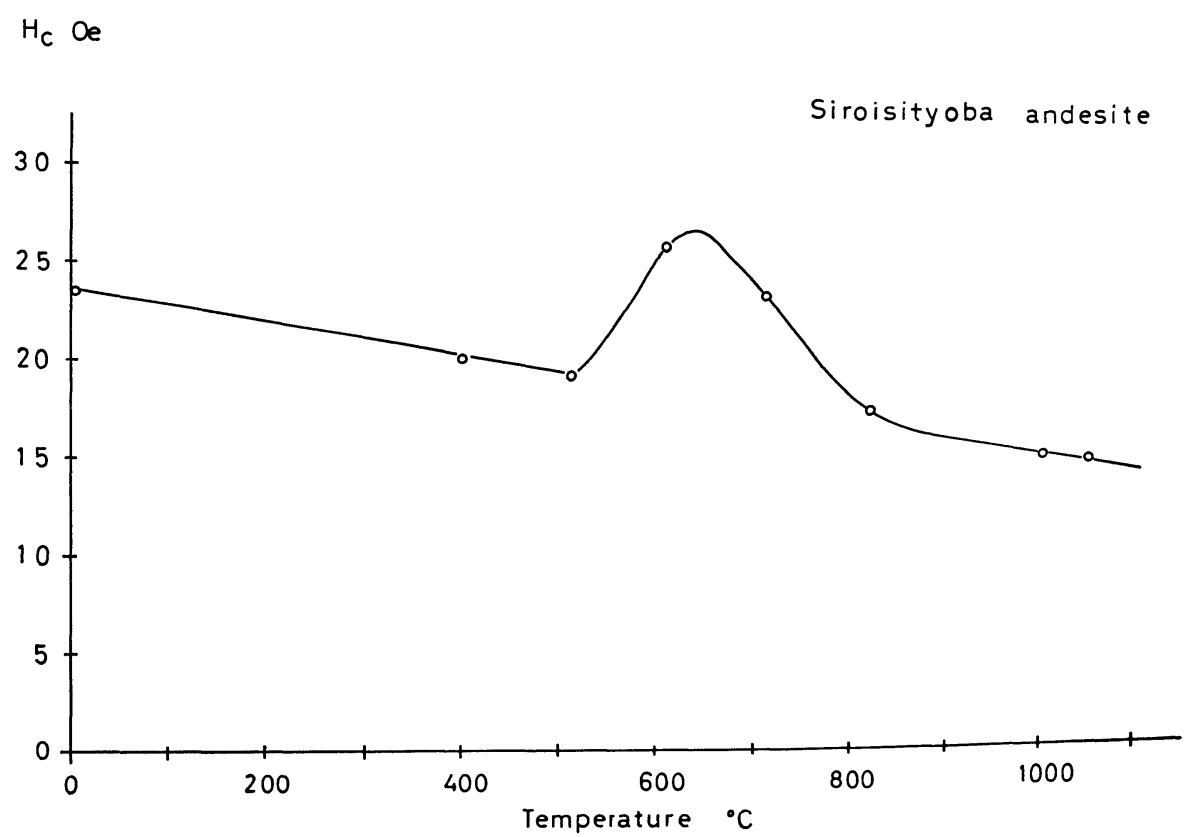

Fig. 2-b Coercive force (measured at room temperature) of heat-treated samples (Siroisityoba) at various temperatures in vacuum of about $10^{-3} \mathrm{mmHg}$ (the same samples as in Fig. 2-a). Coercive force is plotted against the temperature at which the sample was heat-treated.

Table 2 .

\begin{tabular}{l|l|c|c}
\hline & original & heat-treated \\
\hline \multicolumn{2}{l|}{ Curie point } & $500^{\circ} \mathrm{C}$ & $380^{\circ} \mathrm{C}$ \\
\hline \multicolumn{2}{l|}{ lattice parameter } & $8.430 \mathrm{~A}$ & $8.430 \mathrm{~A}$ \\
\hline \multirow{2}{*}{ chemical } & $\mathrm{FeO}$ & $54.5 \mathrm{~mol} \%$ & $54.5 \mathrm{~mol} \%$ \\
composition & $\mathrm{Fe}_{2} \mathrm{O}_{3}$ & 31.4 & 31.0 \\
& $\mathrm{TiO}_{2}$ & 14.1 & 14.5 \\
\hline
\end{tabular}

composition of the magnetic separates from the Siroisityoba andesite are compared for the original and the heat-treated samples; essentially no change can be detected.

Below, the features characteristic of samples which show such irreversible changes are summarised.

(i) Both the Curie point and the magnetic moment decrease during the initial heating $\left(T>500^{\circ} \mathrm{C}\right)$ in vacuum $\left(\sim 10^{-3} \mathrm{mmHg}\right)$. The change in the Curie point amounts to about $100^{\circ} \mathrm{C}$ but the change in the magnetic moment is usually less than $10 \%$. After the sample is once heated up to the Curie point and then cooled in vacuum, however, no further change in the Curie point and the magnetic moment is observed.

(ii) Measurement of the saturation magnetization at low temperatures ( $T=$ room temperature $\sim-196^{\circ} \mathrm{C}$ ) of the original samples indicates that they do not contain a measurable amount of ulvöspinel $\left(\mathrm{Fe}_{2} \mathrm{TiO}_{4}\right)$ as a separate phase. During the initial heating, at 




Fig. 3 Curie point versus $\mathrm{TiO}_{2}$ content of various samples.

-Curie point of synthesized titanomagnetie series.

$\bigcirc-$ Curie point of the natural samples studied in this paper.

$A$ : original, $B$ : heat-treated.

Numbers indicate sample number as in Table 1.

temperatures above about $400^{\circ} \mathrm{C}$, some samples show a kink in their thermomagnetic curves, indicating the existence of two magnetic phases. Other samples, on the other hand, do not show such a kink.

(iii) In contrast with natural samples, synthesized single-phase titanomagnetite does not show an irreversible downshift in the Curie point and the saturation magnetization on heating. In Fig. 3, a solid line represents the relationship between the Curie point and the $\mathrm{TiO}_{2}$ content for synthesized titanomagnetite. In the same figure, the Curie point versus $\mathrm{TiO}_{2}$ content of natural samples are indicated, the original samples by $A_{1}, A_{2}, A_{3}, \ldots \ldots$ and the heat-treated ones by $B_{1}, B_{2}, B_{3}, \ldots \ldots$. As shown, the original (natural) sample has a higher Curie point than a synthesized one with the same $\mathrm{TiO}_{2}$ content. After heat-treatment, however, the natural sample shows about the same Curie point as the synthesized titanomagnetite.

(iv) The bulk coercivity changes anomalously around the temperature at which the irreversible change begins to take place (Fig. 2-b).

(v) There is no noticeable change in the chemical composition of the magnetic separates between the original and the heat-treated samples (Table 2).

(vi) All polished sections were observed under oil at magnification of $1000 \times$. Microscopic observation also indicates that the titanomagnetite grains of the unheated natural samples do not contain separate phases of ulvöspinel and ilmenite, but do possess an appre- 
ciable amount of titanomaghemite along cracks and grain margins. After heating no traces of titanomaghemite are visible. Generally, in its place is found a very fine irregular mosaic of hematite ( $\alpha$-phase) and titanomagnetite. In apparently more advanced stages, the $\alpha$-phase is present in the (111) octahedral planes of the host titanomagnetite. In a few cases, no discrete hematite is discernible. Rather, the titanomagnetite is somewhat lightened in color - probably from a general fine dissemination of the $\alpha$-phase.

(vii) Both in the original and heat-treated samples, X-ray diffractometer analysis indicates that the principal magnetic mineral is of spinel structure. The lattice parameter generally does not change appreciably: in some cases it increases slightly on heating. Small amounts of a second spinel phase or hexagonal $\alpha$-phase (ilmenite-hematite series) cannot be discerned.

On the basis of the experimental facts (i) through (vii), the following conclusions may be deduced.

The experimental result (v) indicates that the irreversible change does not cause any significant change in the bulk chemical composition. Moreover, the experimental result (ii) and (vi) rule out the possibility of simple homogenization of an ilmenite or ulvöspinel phase with the magnetite phase. The experimental result that such an irreversible change does not occur in any synthesized single-phase titanomagnetite (exp. (iii)) seemingly indicates that the irreversible change is not due to a change of ionic configuration.

Experimental result (vi) clearly indicates the break-down of titanomaghemite ( $\gamma$-phase) in the original sample to the $\alpha$-phase hematite-ilmenite series. The disappearance of the titanomaghemite phase explains the slight decrease of the intensity of the saturation magnetization. The hematite-ilmenite series produced by the breakdown of titanomaghemite in these generally acidic rock samples should practically be non-magnetic inasmuch as the $\alpha$ phase containing less than $50 \% \mathrm{Fe} \mathrm{TiO}_{3}$ are generally antiferromagnetic or parasitically ferromagnetic. As titanomagnetite always has a lower Curie point than the corresponding titanomaghemite produced by the oxidation of the former, the disappearance of the titanomaghemite due to breakdown can also explain the decrease of the Curie point. If this is the case, no chemical change in bulk composition will be expected. Experimental fact (v) supports this explanation.

It should be emphasized that microscopic examination is generally more effective in identifying titanomaghemite coexisting with titanomagnetite than thermomagnetic analysis. For example, some samples show a rather monotonic thermomagnetic curve (exp. (ii)), although both, titanomagnetite and titanomaghemite, are clearly identified under a microscope. Also, because of the similar lattice parameter of titanomaghemite and titanomagnetite and because of the relatively small amount of titanomaghemite (usually less than $10 \%$ of the total ferrimagnetic minerals), it is difficult to identify titanomaghemite by X-ray analysis.

Since the lattice parameter a is generally dependent on the principal phase present, titanomaghemite which is a minor phase may only show as a spur or slight broadening of the diffractometer peak corresponding to the major component, if at all. The titanomaghe- 


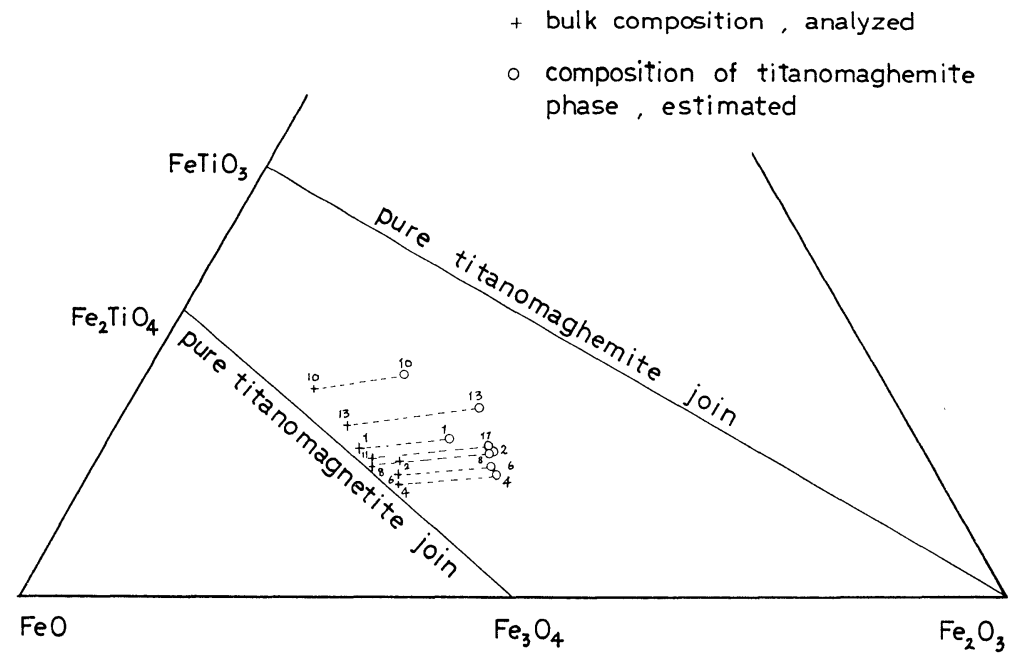

Fig. $4+$ : bulk composition of the samples (chemically analyzed).

$\bigcirc$ : composition of intermediate titanomaghemite phase as determined from $\mathrm{Fe} /(\mathrm{Fe}+\mathrm{Ti})=\mathrm{constant}$ line and maximm Curie point during heating.

Numbers indicate sample number as in Table 1.

mite peak, if present, may also be completely hidden in noise on the diffractometer or in the larger peak area. Hence, it is reasonable to suppose that the lattice parameter does not change significantly before and after the heating unless the titanomaghemite phase was the predominant one. If the titanomaghemite phase present represents not a pure titanomaghemite but rather a phase somewhere intermediate in the titanomagnetite-titanomaghemite solid solution, the effect may just be a slight decrease of the lattice parameter. After heating and collapse of the intermediate $\gamma$-phase the lattice parameter should shift back to a larger value-an expected result consistent with exp. (vii). That all samples analyzed are intermediate members of the titanomagnetite-titanomaghemite series is clearly shown in Fig. 4. The hematite phase after the heat-treatment was not identified by X-ray analysis (exp. (vii)). Similarly, because of the very small amount of the hematite phase present, its peaks will also be hidden in the background.

Experimental fact (iii), that is, the Curie point after the heating is identical with that of the synthesized pure titanomagnetite, also supports the above explanation.

The change in coercive force values during heating (exp. (iv)) may be explained as follows. The first stage of the breakdown of titanomaghemite to $\alpha$-phase will result in an irregular mosaic of grain walls in the titanomagnetite. This would cause an increase in the number of small grains and one might expect an increase in coercive force. With continued heating, these walls apparently diffuse into the (111) plane and form a few relatively thick $\alpha \mathrm{Fe}_{2} \mathrm{O}_{3}$ lamellae. This would correspondingly decrease the number of small grains and the coercive force would decrease again.

It is noteworthy that even with a considerable change in Curie point, that is, more than $100^{\circ} \mathrm{C}$, the decrease in intensity of saturation magnetization is rather insignificant. This is 
in part due to the fact that the titanomaghemite phase constitutes only a small percentage of the ferrimagnetic minerals. For members of the $\mathrm{Fe}_{2} \mathrm{TiO}_{4}-\mathrm{Fe}_{3} \mathrm{O}_{4}$ solid solution series the Curie point is generally raised by oxidation, whereas the equal- $J_{s}$ lines are almost parallel to the oxidation-reduction lines, particularly in the region of low-Ti content. For most rocks, especially low- $T i$ acidic ones, there is really little increase in the $J_{S}$ as maghemitization occurs. Furthermore, as will be discussed later, in the process of the breakdown of a titanomaghemite phase which is somewhere intermediate between pure titanomagnetite and pure titanomaghemite to an $\alpha$-phase some pure titanomagnetite is produced, thereby augmenting the amount originally present in the sample. Therefore, any breakdown of an intermediate member of the titanomaghemite-titanomagnetite series which comprises only $10 \%$ or so of the total opaques will not alter the overall $J_{s}$ value to any large extenet. This again explains the experimental fact ( $i$ ) that the decrease in the $J_{S}$ value is rather small.

\section{Discussion}

As seen in Figure 4 the titanomaghemite phase in all rock samples is not a high-grade titanomaghemite but has a chemical composition between the $\mathrm{Fe}_{2} \mathrm{TiO}_{4}-\mathrm{Fe}_{3} \mathrm{O}_{4}$ and $\mathrm{Fe} \mathrm{TiO}_{3}$ $\mathrm{Fe}_{2} \mathrm{O}_{3}$ joins. Here, by high-grade titanomaghemite or pure titanomaghemite, we mean a titanomaghemite ( $\gamma$-phase) in which the maximum possible amount of oxidation has occurred and which, therefore, plots on or close to the $\mathrm{Fe} \mathrm{TiO}_{3}-\mathrm{Fe}_{2} \mathrm{O}_{3}$ join.

It is well established that there is a complete solid solution between $\mathrm{Fe}_{3} \mathrm{O}_{4}$ and $\mathrm{\gamma Fe}_{2} \mathrm{O}_{3}$, and also between titanomagnetite and corresponding pure titanomaghemite. It is also well established that upon heating to elevated temperatures titanomagnetite does not decompose whereas titanomaghemite undergoes decomposition to the $\alpha$-phase. It is quite evident that if titanomaghemite of intermediate composition is to alter at elevated temperatures some internal process of redistribution must be operative. It is postulated that at high enough temperatures, oxygen vacancies in the intermediate titanomaghemite migrate freely to some concentration centers to form molecules and groups of molecules of nearly pure titanomaghemite which would readily decompose to the $\alpha$-phase if temperatures are above the transition point. At the same time, the $F e$ ions would migrate and fill the position left by the migrating vacancies to produce essentially unoxidized titanomagnetite. In short, heating of an intermediate titanomaghemite will lead both to pure titanomagnetite and to pure titanomaghemite (which will subsequently decompose as it). This process involves no change in total chemical composition, merely a redistribution of ions and vacancies. Let us consider an example, in which the intermediate titanomaghemite is a solid solution of $2 / 3$ titanomagnetite and $1 / 3$ of titanomaghemite, that is, the composition is uniform and expressed as ( 0.66 pure titanomagnetite $)+(0.33$ pure titanomaghemite). When this intermediate titanomaghemite is heated, it will eventually decompose into $2 / 3$ of pure titanomagnetite and $1 / 3$ of pure titanomaghemite. The latter will further break down to the appropriate $\alpha$ phase. Finally, we will have $2 / 3$ of titanomagnetite and $1 / 3$ of the $\alpha$-phase. It is evident that any volume of an intermediate member of the titanomagnetite-titanomaghemite series originally present will yield a smaller volume of breakdown product ( $\alpha$-phase) than the 
amount of the intermediate phase originally present. For the actual cases studied, the composition of the intermediate titanomaghemite is more close to that of titanomagnetite than to pure titanomaghemite (Fig. 4), and accordingly the decomposition of the intermediate phase can only produce a relatively small fraction of the $\alpha$-phase. This probably explains why X-ray analysis fails to show the existence of an $\alpha$-phase in the heated samples.

Certain rocks contain large quantities of titanomaghemite; yet they still show a reversible thermomagnetic curve. An example of such behaviour is the Sidara dolerite which was studied by Akimoto and Kushiro (1960). This apparently contradictory phenomenon is explained by considering the fact that the critical temperature of inversion of the $\gamma$-phase to the $\alpha$-phase in vacuum (about $10^{-3} \mathrm{mmHg}$ ) depends on the $\mathrm{TiO}_{2}$ content of the titianomaghemite. The richer in $\mathrm{TiO}_{2}$, the higher becomes the transformation temperature of titanomaghemite, provided that the pressure is constant (Kushiro, personal communication). The Sidara dolerite, which contains high-grade titanomaghemite with about $30 \mathrm{~mol} \%$ of $\mathrm{TiO}_{2}$, has a transformation temperature much higher than its Curie point, the latter about $600^{\circ} \mathrm{C}$. Hence, heating of the dolerite up to $600^{\circ} \mathrm{C}$ should not result in any irreversible change of the thermomagnetic curve. For the samples used in the present study the $\mathrm{TiO}_{2}$ content generally ranges from 10 to $20 \mathrm{~mol} \%$, and the transformation point is nearly the same as or slightly lower than the Curie point. Hence, heating of these samples to their Curie points certainly results in irreversible changes. If a titanomaghemite which contains less than $10 \%$ $\mathrm{TiO}_{2}$ coexists with titanomagnetite, an irreversible change would probably not occur on heating, inasmuch as the titanomaghemite would be converted to the $\alpha$-phase far below the Curie point of the titanomaghemite.

\section{Conclusion}

It is found that the saturation magnetization and Curie point of some ferrimagnetic minerals of some acidic rocks (andesite, dacite, etc.) decrease irreversibly when the rocks are heated in vacuum $\left(\sim 10^{-3} \mathrm{mmHg}\right)$. X-ray and chemical analyses do not show any distinct differences between the original and the heat-treated samples. However, microscopic observation of polished sections clearly shows that intermediate titanomaghemite which is present abundantly in the original sample is lacking from the heat-treated sample.

During heating the $\gamma$ - to $\alpha$-phase transition has been exceeded and by diffusion of vacancies and $F e$ ions in the intermediate titanomaghemite some pure titanomaghemite forms, molecule by molecule, which immediately inverts to the $\alpha$-phase. The final product is a relatively pure titanomagnetite in which there is a fine intergrowth of the $\alpha$ hematiteilmenite series.

This process, supported by microscopic observation, provides an explanation of all experimental data related to irreversible thermomagnetic changes.

\section{Acknowledgement}

This study was begun by Prof. S. Akimoto when he was in the Geophysical Institute, University of Tokyo, but was interrupted by his transfer to the Institute for Solid State 
Physics, University of Tokyo. He suggested the problem to us and we are very grateful to him for unpublished data and samples. We wish also to thank Prof. T. Nagata for his interest in this study, and Prof. H. Kuno, Geological Institute, University of Tokyo, who provided some rock samples. The chemical analyses were carried out by Dr. M. Yoshida, Tokyo Institute of Technology, to whom the authors are very grateful. Dr. Minoru Ozima should be acknowledged for his critical reading of this manuscript.

\section{References}

Akimoto, S., Magnetic susceptibility of ferromagnetic minerals contained in igneous rocks, J. Geomag. Geoelectr., 3, 47-58, 1951.

Akimoto, S., Magnetic properties of ferromagnetic minerals contained in igneous rocks, Jap. J. Geophys., 1, 1-31, 1955.

Akimoto, S. and T. Katsura, Magneto-chemical study of the generalized titanomagnetite in volcanic rocks. J. Geomag. Geoelectr., 10, 69-90, 1959.

Akimoto, S. and I. Kushiro, Natural occurrence of titanomaghemite and its relevance to the unstable magnetization of rocks, J. Geomag. Geoelectr., 11, 94-110, 1960.

Buddington, A.F. and D.H. Lindsley, Iron-titanium oxide minerals and synthetic equivalents, J. Petrol., 5, 310-357, 1964.

Larson, E.E., Mituko Ozima, Minoru Ozima, T. Nagata and D. Strangway, Geophysical Journal. (in press) Nagata, T., Rock Magnetism, Maruzen, Tokyo, 1961. 